\title{
Breath biomarkers in idiopathic pulmonary fibrosis: a systematic review
}

\author{
Conal Hayton ${ }^{1,3^{*}}$ D, Dayle Terrington ${ }^{2}$, Andrew M. Wilson ${ }^{2}$, Nazia Chaudhuri ${ }^{3}$, Colm Leonard ${ }^{3}$ and \\ Stephen J. Fowler ${ }^{1,3}$
}

\begin{abstract}
Background: Exhaled biomarkers may be related to disease processes in idiopathic pulmonary fibrosis (IPF) however their clinical role remains unclear. We performed a systematic review to investigate whether breath biomarkers discriminate between patients with IPF and healthy controls. We also assessed correlation with lung function, ability to distinguish diagnostic subgroups and change in response to treatment.

Methods: MEDLINE, EMBASE and Web of Science databases were searched. Study selection was limited to adults with a diagnosis of IPF as per international guidelines.

Results: Of 1014 studies screened, fourteen fulfilled selection criteria and included 257 IPF patients. Twenty individual biomarkers discriminated between IPF and controls and four showed correlation with lung function. Meta-analysis of three studies indicated mean $( \pm S D)$ alveolar nitric oxide $\left(C_{a l v} N O\right)$ levels were significantly higher in IPF $(8.5 \pm 5.5 \mathrm{ppb})$ than controls $(4.4 \pm 2.2 \mathrm{ppb})$. Markers of oxidative stress in exhaled breath condensate, such as hydrogen peroxide and 8-isoprostane, were also discriminatory. Two breathomic studies have isolated discriminative compounds using mass spectrometry. There was a lack of studies assessing relevant treatment and none assessed differences in diagnostic subgroups.
\end{abstract}

Conclusions: Evidence suggests $C_{\text {alv }} N O$ is higher in IPF, although studies were limited by small sample size. Further breathomic work may identify biomarkers with diagnostic and prognostic potential.

Keywords: Idiopathic pulmonary fibrosis, Breath tests, Nitric oxide, Volatile organic compounds, Exhaled breath condensate

\section{Introduction}

Idiopathic pulmonary fibrosis (IPF) is the most common form of interstitial lung disease (ILD) with an estimated incidence of 2.8-9.3 per 100,000 per year in Europe and North America [1]. It is associated with high morbidity and mortality with a reported median survival of approximately three years [2]. Challenges exist, particularly in relation to diagnosis and clinical phenotyping [3, 4]. Diagnostic criteria for IPF have evolved over time and have recently been updated [5]. There is risk of misdiagnosis, particularly as inter-observer agreement amongst

\footnotetext{
* Correspondence: conalhayton@doctors.org.uk

'Division of Infection, Immunity and Respiratory Medicine, School of Biological Sciences, Faculty of Biology, Medicine and Health, The University of Manchester, Manchester, UK

${ }^{3}$ North West Lung Centre, Manchester University NHS Foundation Trust, Manchester, UK

Full list of author information is available at the end of the article
}

clinicians is variable $[6,7]$. Surgical biopsy rates remain low due to concerns regarding associated mortality and morbidity, particularly in an elderly, comorbid patient group [8]. In addition, it is well recognised that significant heterogeneity exists within the IPF population in relation to disease progression $[9,10]$. At present, lung function parameters remain the most widely used tool to monitor disease activity in IPF and the most commonly used end point in therapeutic trials [11]. An absolute annual decline in forced vital capacity (FVC) of $10 \%$ or diffusion capacity for carbon monoxide $\left(\mathrm{D}_{\mathrm{LCO}}\right)$ of $15 \%$ has been shown to be an accurate predictor of mortality in IPF [12-14]. However, baseline FVC measurements do not have strong prognostic value and limitations exist with respect to interpretation of longitudinal changes $[15,16]$. Baseline $D_{\text {LCO }}$ may be slightly better at predicting mortality in IPF [2], however results may be

(C) The Author(s). 2019 Open Access This article is distributed under the terms of the Creative Commons Attribution 4.0 International License (http://creativecommons.org/licenses/by/4.0/), which permits unrestricted use, distribution, and 
significantly affected by the presence of co-morbidity, such as pulmonary hypertension and emphysema [17]. Other physiological parameters associated with disease prognosis include total lung capacity (TLC) and 6-min walk distance [14, 18]. Composite scoring systems such as the Composite-Physiologic Index (CPI) and Gender Age Physiology (GAP) index [19, 20], which incorporate demographic and physiological data, may represent more accurate prognostic models.

It is recognised that there is a need for additional biomarkers to augment the diagnostic process, facilitate clinical phenotyping, improve accurate disease monitoring and identify potential therapeutic targets in IPF [21, 22].

Several serological markers, including Krebs von den Lungen-6 (KL-6), Surfactant protein-A (SP-A) and D (SP-D), and matrix metalloproteinase-7 (MMP-7) have been identified as having potential diagnostic and prognostic value [23-28], while the PROFILE (Prospective Observation of Fibrosis in the Lung Clinical Endpoints) study, an ongoing prospective multicentre study aimed at biomarker discovery, has identified further novel serological protein markers with prognostic potential $[29,30]$.

Exhaled breath may represent an alternative source of novel biomarkers in IPF. There has been an interest in breath research in respiratory disease for many years [31]. In asthma, exhaled nitric oxide (NO) has successfully transitioned from research to clinical practice and its use is now recommended in international clinical guidelines for diagnosis and monitoring [32-35]. Fractionated exhaled nitric oxide measured at a flow rate of $50 \mathrm{ml} / \mathrm{s}$ $\left(\mathrm{FeNO}_{50}\right)$ using either a chemiluminescence, electrochemical or laser analyser is used as a surrogate marker of inflammation in the airways [33]. Capturing FeNO at different flow rates also allows estimation of the concentration of $\mathrm{NO}$ at the level of the alveolus $\left(\mathrm{C}_{\text {alv }} \mathrm{NO}\right)$ and airway wall $\left(\mathrm{C}_{\mathrm{aw}} \mathrm{NO}\right)$, as well as diffusion capacity $\left(\mathrm{D}_{\mathrm{aw}} \mathrm{NO}\right)$ and airway flux $\left(\mathrm{J}_{\mathrm{aw}} \mathrm{NO}\right)[36,37]$. An alternative medium for breath sampling is exhaled breath condensate (EBC), which is comprised of condensed water vapour with small amounts of non-volatile and water-soluble volatile molecules within [38, 39]. Following collection, relevant analytes can be measured using specific assays or mass spectrometry [39]. More recently, interest in volatile organic compounds (VOCs) as a potential source of biomarkers in respiratory disease has been gathering pace [40-43]. In particular high-throughput "breathomics" using gas chromatography-mass spectrometry (GC-MS), may allow discovery of novel volatile compounds with highly specific diagnostic, therapeutic or prognostic potential $[40,42]$. These methods have been used to identify VOCs in a number of respiratory diseases including asthma [44], COPD [45], pneumonia [46] and lung cancer [47]. Electronic noses ("E-noses"), sensors which detect specific patterns of VOCs, have also been tested in a number of respiratory conditions and may represent a more clinically accessible diagnostic tool [48]. Figure 1 details the breadth of current approaches for breath analysis.

Breath sampling represents an attractive investigative method, being both non-invasive, simple to collect and unlimited in quantity. However, the utility of breath analysis in IPF is unclear. The aim of this systematic review was to investigate the role of breath biomarkers in IPF. The primary aim was to establish which breath biomarkers are significantly different in the IPF population compared to healthy controls. We also hoped to answer whether biomarkers correlate with lung function parameters within the IPF population, differ between treated and untreated patients and between patients with and without honeycombing.

\section{Materials and methods}

We performed this systematic review using PRISMA (Preferred Reporting Items for Systematic Reviews and Meta-Analyses) guidelines [49]. The review was registered with the International prospective register of systematic reviews (PROSPERO) (Registration ID CRD42017078645).

\section{Search strategy and study selection}

Two reviewers performed independent electronic database searches in January 2018. Databases searched were MEDLINE (using both PubMed and Ovid), EMBASE and Web of Science. Searches were performed using a combination of MeSH and key word terms. The search terms used were (idiopathic pulmonary fibrosis OR pulmonary fibrosis OR lung diseases, interstitial OR fibrosing alveolitis OR diffuse parenchymal lung disease OR usual interstitial pneumonia) AND (breath tests OR volatile organic compounds OR metabolomics OR breath analysis OR breath biomarkers OR breathomics OR exhaled breath).

Study selection was performed based on the following eligibility criteria. Inclusion criteria were: age over 18; a diagnosis of idiopathic pulmonary fibrosis based on international guidelines[2, 50]; primary research involving breath biomarkers; comparison control group of healthy participants or comparison within IPF population based on lung function or treatment strategy. Exclusion criteria were: non-human studies; review articles; research in abstract form only; non-english language publications. Each reviewer performed abstract and full text review to identify studies which met selection criteria. Reference lists of retrieved articles were reviewed to identify additional papers. Google Scholar (https://scholar.google.co.uk) was used to identify any additional articles which may have cited the retrieved articles. 


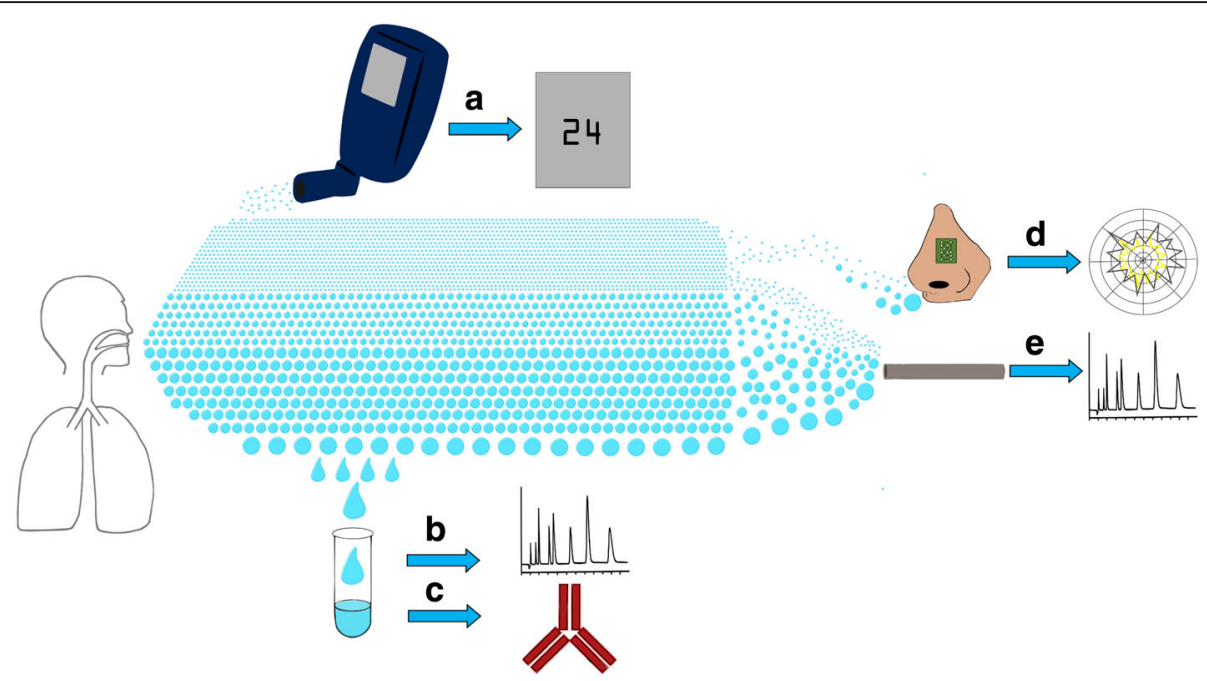

Fig. 1 The spectrum of breath analysis. Exhaled breath contains a vast quantity of molecules and particles, ranging in size and volatility, which can be captured using analytical techniques. Nitric oxide is a very small, volatile compound which can be detected using an online analyser which will provide an instant measurement of the concentration in exhaled breath (a). Large, non-volatile particles can be detected in exhaled breath condensate, either through liquid chromatography-mass spectrometry (b) or enzyme immunoassay (c). Volatile organic compounds (VOCs) of varying size can be detected by using various technologies including electronic noses (d) or gas-chromatography mass spectrometry (e)

\section{Data extraction and quality assessment}

Data extraction and quality assessment of all the selected studies was performed independently by both reviewers. Quality was assessed using the QUADAS-2 tool [51]. This facilitates the assessment of studies of diagnostic tests for bias and applicability in four domains; patient selection, index test, reference test and flow and timing. In this review, the index test was the biomarker under investigation and the reference test was a diagnosis of IPF based on international guidelines $[2,50]$.

Data extraction was performed using an electronic data collection form. Data collected included country and year of publication, method of breath collection and analytical technique, number of IPF and control patients, baseline characteristics (e.g. age, gender, smoking status) and significant differences between groups, treatment regimens, reported lung function parameters, biomarker levels and reported differences between groups.

All studies identified were included in qualitative data synthesis. Quantitative data synthesis was performed where three or more studies reported the same outcome. This consisted of random effects meta-analysis of mean difference in biomarker levels (IPF vs controls) with $\mathrm{I}^{2}$ statistic to assess heterogeneity. Reported mean and standard deviation (SD) of biomarker levels were included in the analysis. If studies reported standard error (SE), this was converted to SD. Statistical analysis was performed using OpenMeta-Analyst software [52].

\section{Results}

Following removal of duplicates, we identified 1014 articles through databases searches, reference lists and citing articles. The results for each database searched can found in Additional file 1. Title and abstract screening identified 53 articles for full text review of which 39 did not fulfil selection criteria for data analysis (See Additional file 2 for details). Fourteen studies were included in qualitative data synthesis and three were included in quantitative data synthesis. Figure 2 summarises the search results.

The 14 studies included a total of 257 patients with idiopathic pulmonary fibrosis. There was significant heterogeneity within the included studies in terms of study design, breath analysis technique and biomarkers investigated. Sixty-seven targeted biomarkers were measured with additional non-targeted metabolomic studies. Table 1 summarises the results of the included studies with reference to the primary and secondary research questions. None of the studies included in this review made comparison between IPF patients with evidence of honeycombing and those without documented honeycombing.

\section{Study quality and risk of bias}

Figure 3 summarises the risk of bias and applicability concern across the domains of the QUADAS- 2 tool. The quality assessment for each study using the QUADAS-2 tool is presented in Additional file 3. In general, there were significant issues with bias particularly concerning patient selection. The majority of the studies were of a case-control design, however controls were frequently not matched for age and smoking status, both of which have been shown to influence results of breath analysis [53]. Sample sizes were small across the spectrum of studies included with the number of IPF patients 


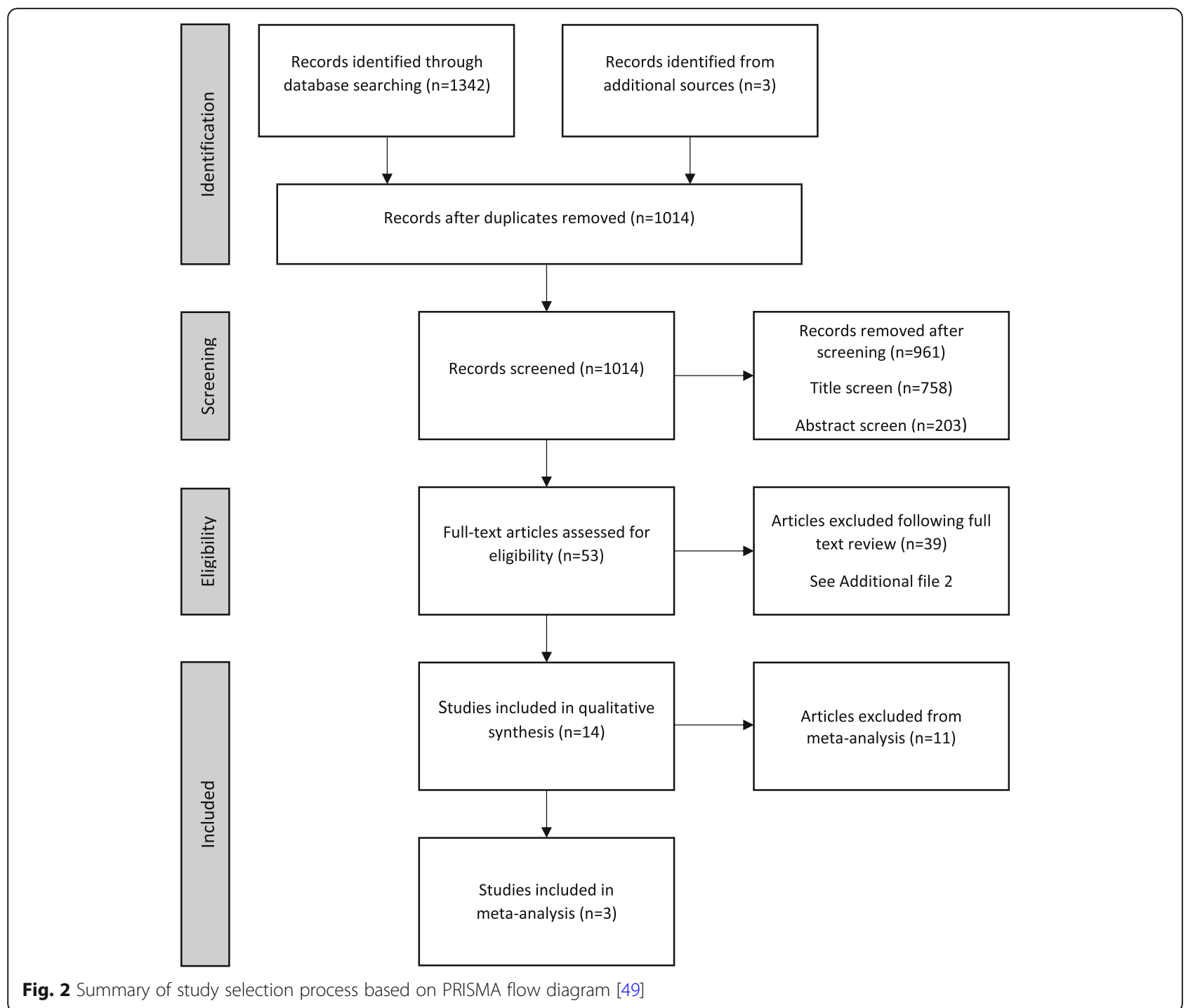

ranging from 6 to 40 . No power calculations were reported in any of the studies. Tests of breath biomarkers are prone to contamination from several sources including environmental, nasal and oral [53]. There was wide variation on how these were controlled, and the degree of methodological detail provided. There was also variation in the analytical equipment and/or assays used, which has also been shown to influence results and makes comparison between studies more difficult [39, $53,54]$.

\section{Qualitative data synthesis}

\section{Which breath biomarkers are significantly different in the} IPF population compared to healthy controls?

Twelve studies compared breath biomarkers in IPF compared to healthy controls. Twenty biomarkers were found to discriminate between IPF patients and healthy controls. These are listed in Table 2.
Exhaled nitric oxide was measured in three studies; [55-57] two studies reported both $\mathrm{FeNO}_{50}$ and $\mathrm{C}_{\text {alv }} \mathrm{NO}$ $[55,57]$, and a third reported solely $\mathrm{C}_{\mathrm{alv}} \mathrm{NO}$. [56] Furukawa et al [55] found no difference in $\mathrm{FeNO}_{50}$ levels in IPF patients compared to controls, although the two groups were not well matched for gender or smoking history. Cameli et al [57] found that FeNO levels were higher in patients with IPF at flow rates of $50 \mathrm{ml} / \mathrm{s}$ as well as $100 \mathrm{ml} / \mathrm{s}\left(\mathrm{FeNO}_{100}\right)$ and $150 \mathrm{ml} / \mathrm{s}\left(\mathrm{FeNO}_{150}\right)$. These two studies, along with a study by Zhao et al, [56] also reported $\mathrm{C}_{\mathrm{alv}} \mathrm{NO}$ in patients with IPF and healthy controls (see quantitative data synthesis).

Eight studies measured biomarkers present in EBC in patients with IPF and healthy controls [55, 58-64]. These included markers of oxidative stress [8-isoprostane, hydrogen peroxide $\left(\mathrm{H}_{2} \mathrm{O}_{2}\right)$, malondialdehyde (MDA)], markers of nitrosative stress (nitrite and nitrate), metallic elements, and cytokines. Two studies 


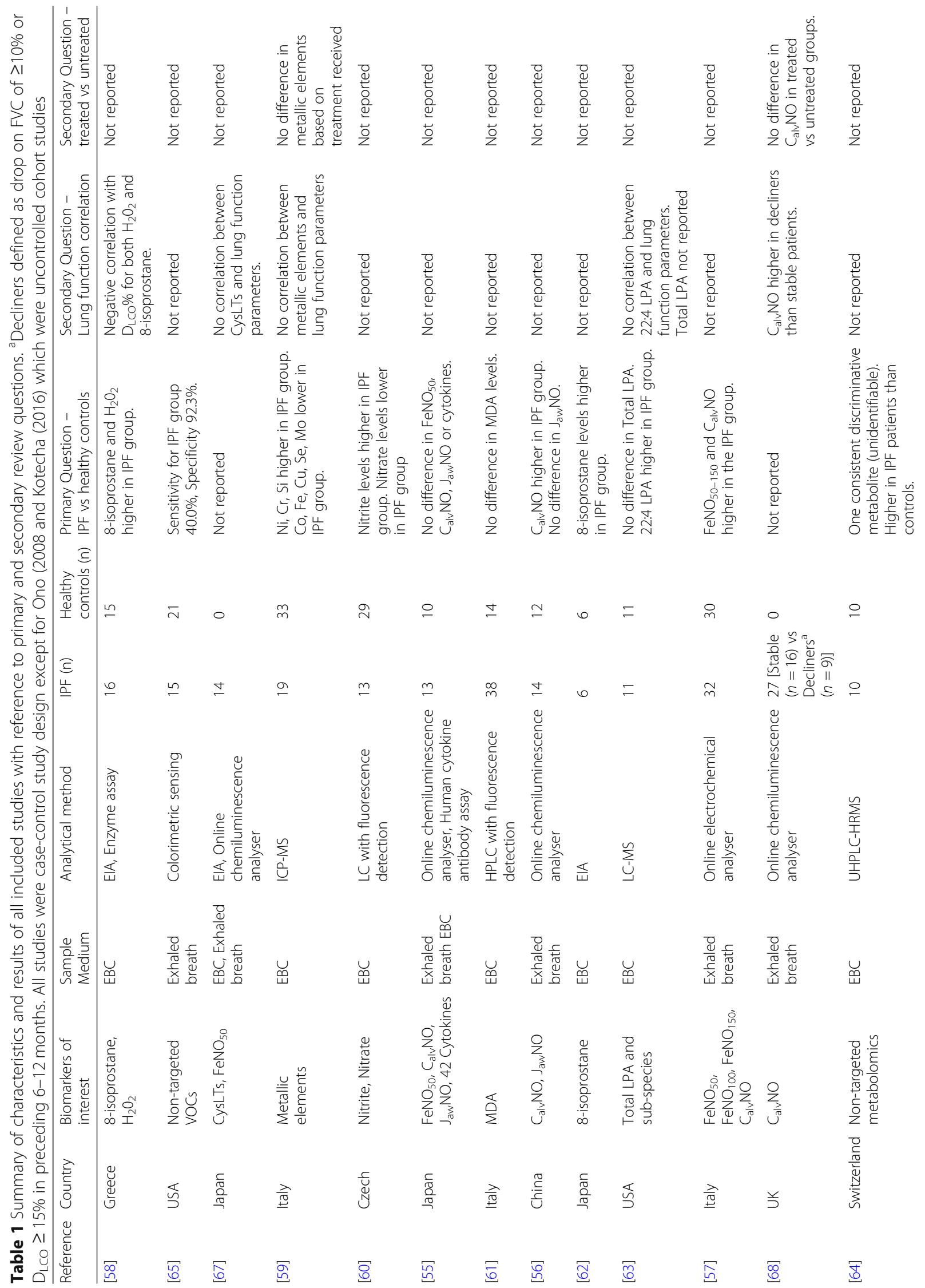




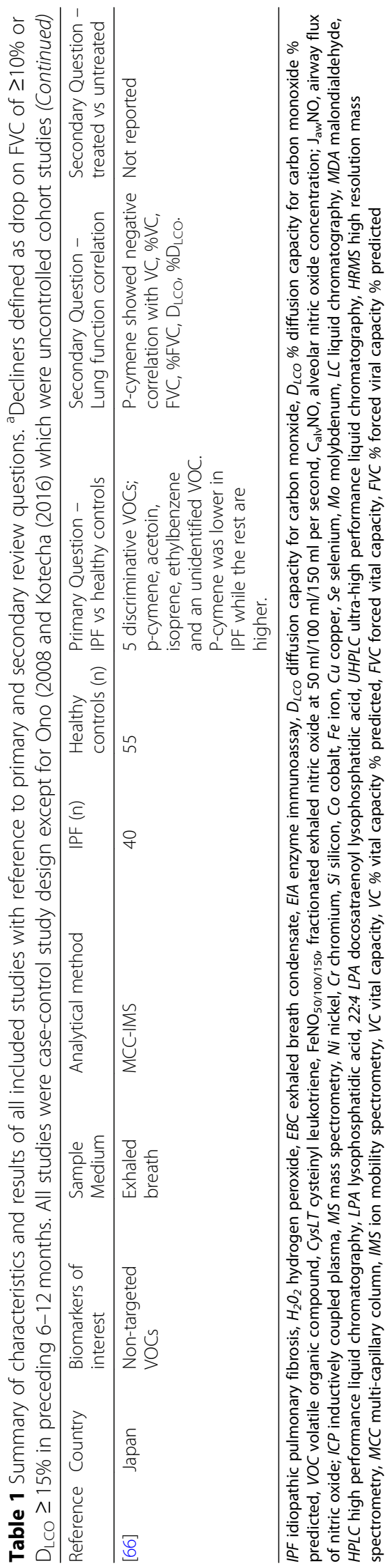



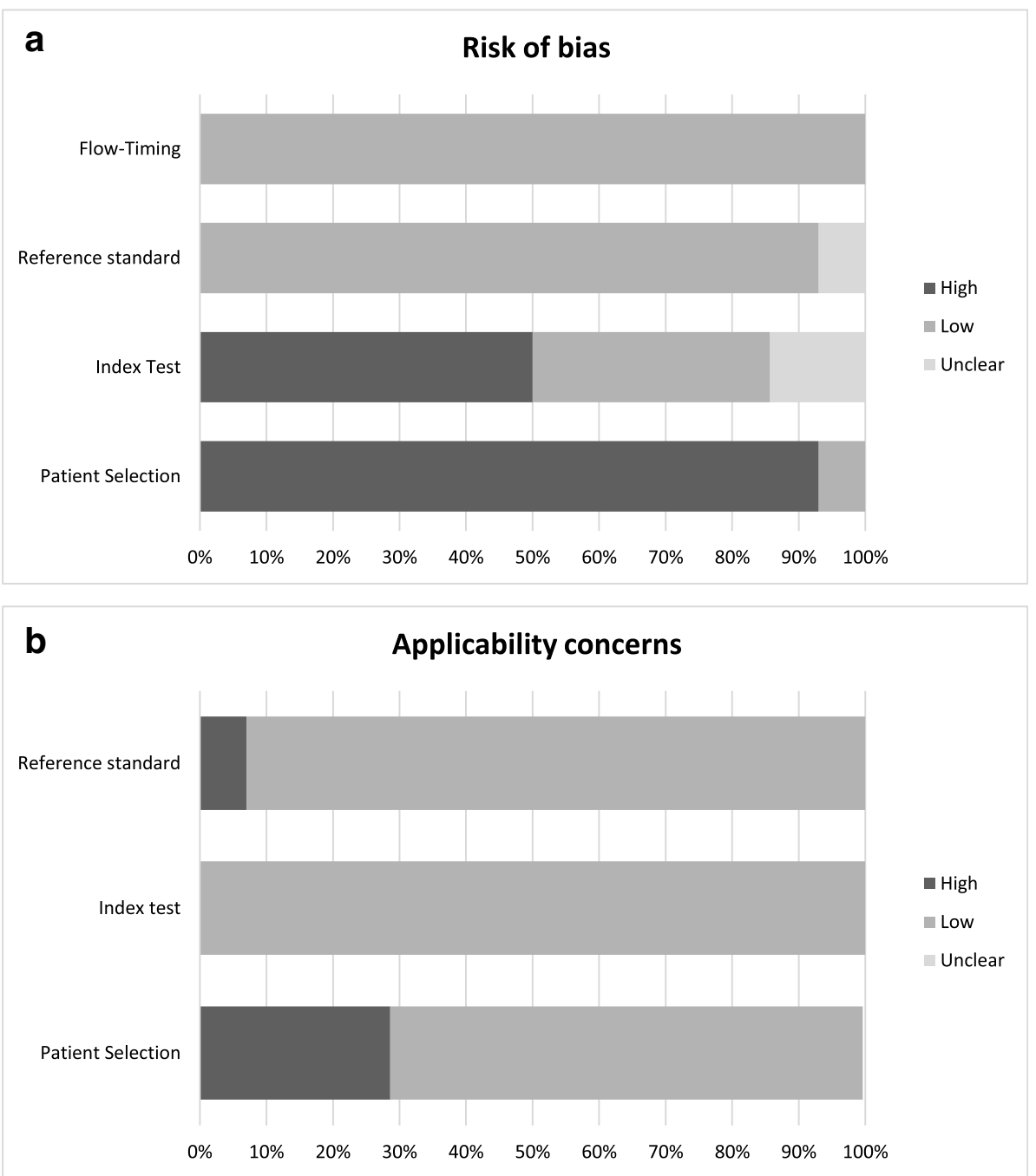

Fig. 3 Proportion of studies included with high, low or unclear risk of bias (a) and applicability concerns (b) as per QUADAS-2 tool

found significantly higher levels of 8-isoprostone in IPF patients $(25-74 \mathrm{pg} / \mathrm{mL})$ compared to controls $(5-33 \mathrm{pg} /$ $\mathrm{mL})[58,62]$. One study investigated lysophosphatidic acid (LPA) species in EBC from 11 IPF patients and 11 healthy controls using liquid chromatography-tandem mass spectrometry to identify the presence of total LPA and subspecies of LPA [63]. There was no difference in total LPA levels between the two groups but one species, docosatetraenoyl (22:4) LPA, was significantly higher in IPF compared to controls. These results may have been skewed by an outlier patient with extremely high levels of 22:4 LPA. This patient was subsequently hospitalised and treated for an exacerbation of IPF within ten days of collection and received urgent lung transplantation. There were no data presented that excluded this patient. Rindlisbacher et al [64] analysed EBC samples from ten patients with a diagnosis of IPF and ten age-matched controls using ultra high-performance liquid chromatography coupled to high-resolution mass spectrometry to identify discriminative metabolites using a non-targeted approach. A validation set of samples was taken from eight of the IPF patients and eight additional controls. The initial analysis identified 58 metabolic features which were significantly different between the IPF group and the healthy controls with 48 being identified in the validation set. Only two discriminative features were found to be present in both the pilot and the validation sets and of these only one was regulated in the same direction in both sets. This discriminative feature was two-fold up-regulated in IPF compared to healthy controls. They speculated that the potential molecular formula was $\mathrm{C}_{21} \mathrm{H}_{44} \mathrm{~N}_{2} \mathrm{O}$ but were unable to identify a metabolite from known databases.

Two studies assessed VOCs in IPF patients and healthy controls [65, 66]. Yamada et al [66] examined VOCs in breath samples of 40 patients with IPF and 55 healthy controls. Samples were analysed using 
Table 2 Biomarkers reported to discriminate between IPF patients and healthy controls. Direction of discrimination and reported p-value. ${ }^{a} \mathrm{C}_{\mathrm{alv}} \mathrm{NO} .{ }^{\mathrm{b}} \mathrm{FeNO} \mathrm{No}_{5} / \mathrm{FeNO}_{100} / \mathrm{FeNO}_{150} / \mathrm{C}_{\mathrm{alv}} \mathrm{NO}$

\begin{tabular}{|c|c|c|c|c|}
\hline Biomarker & Sample Medium & Discrimination & $p$-value & References \\
\hline Nitric Oxide & Exhaled breath & Higher in IPF & $0.0001,<0.0001$ & {$[62]^{a},[65]^{b}$} \\
\hline 8-isoprostane & EBC & Higher in IPF & $0.02,<0.05$ & [58], [62] \\
\hline Hydrogen Peroxide & EBC & Higher in IPF & 0.003 & [58] \\
\hline Nickel & EBC & Higher in IPF & $<0.05$ & [59] \\
\hline Chromium & EBC & Higher in IPF & $<0.05$ & \\
\hline Silicon & EBC & Higher in IPF & $<0.05$ & \\
\hline Cobalt & EBC & Lower in IPF & $<0.05$ & \\
\hline Iron & EBC & Lower in IPF & $<0.05$ & \\
\hline Copper & EBC & Lower in IPF & $<0.05$ & \\
\hline Selenium & EBC & Lower in IPF & $<0.05$ & \\
\hline Molybdenum & EBC & Lower in IPF & $<0.05$ & \\
\hline Nitrite & EBC & Higher in IPF & $<0.01$ & [60] \\
\hline Nitrate & EBC & Lower in IPF & $<0.01$ & \\
\hline 22:4 LPA & EBC & Higher in IPF & 0.001 & [63] \\
\hline Unidentifiable metabolite & EBC & Higher in IPF & $\leq 0.01$ & [64] \\
\hline p-cymene & Exhaled breath & Lower in IPF & $<0.001$ & [66] \\
\hline Acetoin & Exhaled breath & Higher in IPF & $<0.001$ & \\
\hline Isoprene & Exhaled breath & Higher in IPF & $<0.001$ & \\
\hline Ethylbenzene & Exhaled breath & Higher in IPF & $<0.001$ & \\
\hline Unidentified VOC & Exhaled breath & Higher in IPF & $<0.001$ & \\
\hline
\end{tabular}

IPF idiopathic pulmonary fibrosis, EBC exhaled breath condensate, 22:4 LPA Docosatetraenoyl lypophosphatidic acid, VOC volatile organic compound, $C_{a l v} N O$ alveolar nitric oxide concentration, $\mathrm{FeNO}_{50 / 100 / 150}$ fractionated exhaled nitric oxide at $50 \mathrm{ml} / 100 \mathrm{ml} / 150 \mathrm{ml}$ per second

multicapillary column ion mobility spectrometry. Through this method they identified 85 VOC peaks in IPF patients and healthy controls, with significant differences in five. They identified these as p-cymene, acetoin, isoprene, ethylbenzene and an unidentified compound (peak 67). P-cymene was found to be lower in patients with IPF while the other compounds were higher in IPF. Isoprene was found to carry the highest diagnostic accuracy. This study was limited by the age difference between the two groups (IPF mean age 70, control mean age 38) and gender differences with a higher proportion of females in the control group. Another study assessed the ability of a colorimetric sensor to detect patterns of VOCs in lung cancer patients [65]. They also included patients with IPF and healthy controls in the cohort. Sensitivity of $40 \%$ and specificity of $93 \%$ for IPF was reported although this was not validated. Diagnosis was confirmed either clinically or histologically, however international guidelines were not referenced.

\section{Do levels of breath biomarkers in the IPF population correlate with lung function parameters?}

Six studies assessed correlation between breath biomarkers and lung function in IPF patients [58, 59, 63, 66-68]. Kotecha et al [68] compared $\mathrm{C}_{\text {alv }} \mathrm{NO}$ levels in 27
IPF patients whose lung function had been declining in the previous 6-12 months to those with stable lung function. $\mathrm{C}_{\mathrm{alv}} \mathrm{NO}$ levels were noted to be significantly higher in the 16 patients with declining lung function. Psathakis et al [58] found a negative correlation with $\mathrm{D}_{\text {LCO }} \%$ predicted with both $\mathrm{H}_{2} \mathrm{O}_{2}$ and 8-isoprostane although no association was noted with other measures of pulmonary function. Yamada et al [66] found that P-cymene had a negative correlation with lung function parameters including FVC and $\mathrm{D}_{\mathrm{LCO}}$. Ethylbenzene had a negative correlation with $\% \mathrm{D}_{\mathrm{LCO}} / \mathrm{VA}$ (diffusion capacity per litre lung volume). No correlation was noted with levels of cysteinyl leukotrienes (CysLTs), Docosatetraenoyl (22:4) LPA or metallic elements in EBC and lung function parameters in IPF $[59,63,67]$.

\section{Do levels of breath biomarkers in the IPF population differ between treated and untreated patients?}

Two studies compared breath biomarkers in IPF patients receiving treatment. Kotecha et al [68], found no difference in $\mathrm{C}_{\mathrm{alv}} \mathrm{NO}$ levels in IPF patients receiving treatment with immunosuppression (either corticosteroids alone or in combination with azathioprine) and untreated patients. Corradi et al [59] found that there was no treatment effect on the presence of 


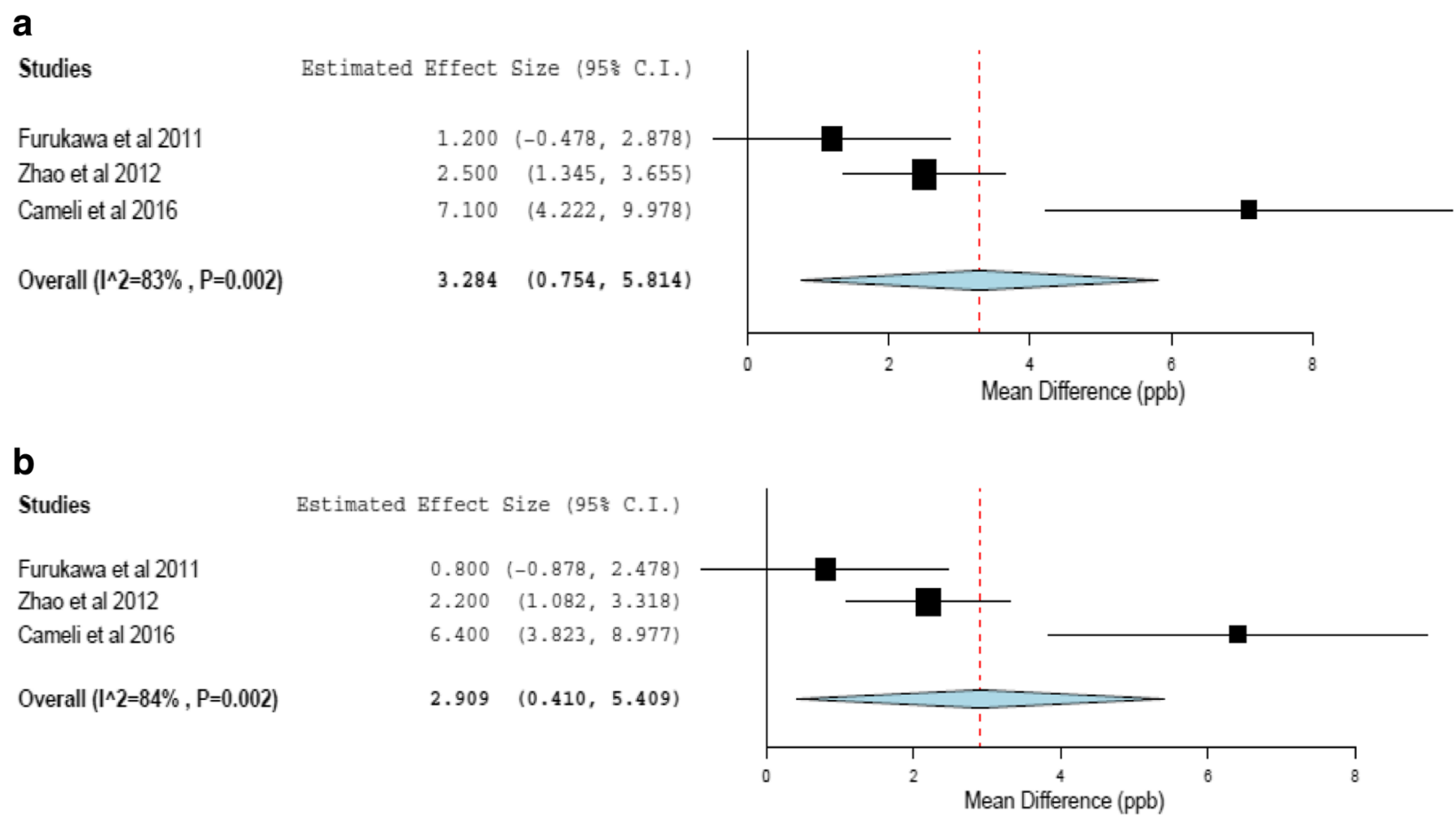

Fig. 4 Random effects meta-analysis of mean difference in CalvNO (ppb) between groups (IPF vs Healthy controls) using Tsoukias and George (a) and Condorelli (b) methods of calculation

metallic elements in EBC of IPF patients. Treatment regimens included steroids, immunosuppression and pirfenidone, although this group of patients included both IPF and non-specific interstitial pneumonia (NSIP) diagnoses, and only two patients were receiving pirfenidone.

\section{Quantitative data synthesis}

Three studies compared $\mathrm{C}_{\mathrm{alv}} \mathrm{NO}$ levels in IPF patients and controls and were included in meta-analysis [5557]. Each study reported $\mathrm{C}_{\mathrm{alv}} \mathrm{NO}$ using both the Tsoukias and George method [36] and corrected for axial diffusion using the Condorelli method [69]. The range of values reported for $\mathrm{C}_{\mathrm{alv}} \mathrm{NO}$ using the Tsoukias and George method was $4.4-11.8 \mathrm{ppb}$ for IPF patients and 2.9-5.1 ppb for healthy controls. Using the Condorelli method the range was 3.9-10. $7 \mathrm{ppb}$ for IPF patients and $1.7-4.5 \mathrm{ppb}$ for healthy controls. We performed meta-analysis to compare mean difference in $\mathrm{C}_{\text {alv }} \mathrm{NO}$ (ppb) levels between IPF patients and healthy controls, using both Tsoukias and George and Condorelli methods. Figure 4 shows the forest plots. Meta-analysis suggested that $\mathrm{C}_{\mathrm{alv}} \mathrm{NO}$ was significantly higher in patients with IPF using either method, however the total number of patients included was small $(n=101)$ and significant heterogeneity between the studies was noted $\left(\mathrm{I}^{2}=83 \% \& 84 \%, p=0.002\right)$.

\section{Discussion}

This systematic review has highlighted the heterogeneity of results from breath research in IPF. Over 60 known biomarkers and multiple unknown molecules have been investigated within a total patient cohort of less than 300 patients using a wide variety of analytical techniques. In this context, it is difficult to draw any firm conclusions regarding potentially clinically relevant markers. Twenty individual biomarkers were reported to discriminate between IPF and healthy controls however most of the studies did not include a validation cohort and there was an absence of longitudinal data. Only two of these biomarkers, exhaled $\mathrm{NO}$ and 8-isoprostane, have been studied more than once.

Exhaled NO is a breath biomarker which is easily measurable and already used in asthma care [32-35]. $\mathrm{NO}$ is a free radical that is implicated in a wide variety of physiological and pathophysiological processes [70]. It has been suggested that NO may increase the expression of pro-fibrotic mediators, such as transforming growth factor- $\beta$ (TGF- $\beta 1$ ), in lung fibrosis [71]. Two studies reported that measurements of exhaled nitric oxide were elevated in IPF compared to healthy controls [56, 57]. This is supported by an additional study which found that exhaled NO levels measured at a non-specific flow rate between 5 and $6 \mathrm{~L} / \mathrm{min}$ were significantly higher in patients with a diagnosis of cryptogenic fibrosing alveolitis (CFA) compared to healthy non-smoking controls 
[72]. This study was excluded from this systematic review as it preceded international standards for IPF diagnosis. In clinical practice $\mathrm{FeNO}_{50}$ is the most common method used for measuring and reporting $\mathrm{NO}$ in breath. NO measured at this flow rate contains a higher proportion of airway and lower proportion of alveolar NO [54]. $\mathrm{FeNO}_{50}$ did not show consistency in IPF, $[55,57]$ or other forms of interstitial lung disease [73, 74]. $\mathrm{FeNO}_{50}$ levels in IPF patients ranged from 20.8-31.5 ppb [55, 57, 67]. It has been reported that the upper limit of $\mathrm{FeNO}_{50}$ in healthy adults ranges from $30.3-50.6 \mathrm{ppb}$ depending on age and gender [75].

Although, $\mathrm{FeNO}_{50}$ is unlikely to be of use in IPF, $\mathrm{C}_{\text {alv }} \mathrm{NO}$ may have potential as a clinical biomarker. Meta-analysis in this review, while limited by small sample size and significant heterogeneity, suggests that $\mathrm{C}_{\mathrm{alv}} \mathrm{NO}$ is higher in IPF patients compared to controls. Average $\mathrm{C}_{\mathrm{alv}} \mathrm{NO}$ levels for patients with IPF were 8.5 $( \pm 5.5) \mathrm{ppb}$ compared to $4.4( \pm 2.2) \mathrm{ppb}$ for healthy controls. In a recent study of 433 healthy individuals, the upper limit of $\mathrm{C}_{\text {alv }} \mathrm{NO}$ reported was 3.88-3.93, depending on age [76]. Elevated alveolar NO supports a pathophysiological role in lung fibrosis. Nitrite, another mediator of nitrosative stress was also elevated in pulmonary fibrosis [60, 77]. $\mathrm{C}_{\text {alv }} \mathrm{NO}$, but not FeNO, has also been reported to be elevated in ILD related to systemic sclerosis [78-80]. Increased exhaled NO levels have been described in other forms of ILD including hypersensitivity pneumonitis (HP), asbestosis and connective tissue disease related ILD (CTD-ILD), limiting the potential of the test as a discriminative diagnostic tool [73, 74, 8185]. An alternative role for $\mathrm{C}_{\mathrm{alv}} \mathrm{NO}$ may be in disease monitoring. Kotecha et al [68] suggested that $\mathrm{C}_{\text {alv }} \mathrm{NO}$ levels were reflective of deteriorating lung function. This is consistent with other studies suggesting that $\mathrm{C}_{\text {alv }} \mathrm{NO}$ levels are inversely related to lung function parameters in fibrotic ILD, a phenomenon not seen with FeNO [73, $81,83]$. However, a paucity of longitudinal data makes it difficult to draw any firm conclusions. Likewise, there is insufficient evidence to suggest a use for NO in monitoring treatment response in IPF. Only one study reported on treatment effect and found no difference in $\mathrm{C}_{\text {alv }} \mathrm{NO}$ levels between patients treated with immunosuppressive therapy and untreated patients [68]. Lower levels of exhaled NO were noted in patients with CFA receiving treatment with oral corticosteroids [72]. In both studies patients were receiving either steroid monotherapy or combination with azathioprine, a treatment regimen which has since been shown to have negative outcomes in IPF and is no longer recommended [86]. No studies have examined exhaled NO levels in patients taking antifibrotic therapy, the treatment of choice for IPF.

Several studies investigated biomarkers in EBC implicated in the pathogenesis of IPF $[55,58-64,67]$.
Oxidative stress is one potential mechanism suggested in the fibrotic process [87]. In vivo, a variety of markers have been used as a surrogate index of oxidative stress [31]. A recent systematic review published in Respiratory Research has identified all the relevant markers of oxidative stress investigated in IPF [88]. These include $\mathrm{H}_{2} \mathrm{O}_{2}$, a reactive oxygen species, and 8-isoprostane, a prostaglandin-like compound formed by lipid peroxidation. Both were found to be elevated in EBC in patients with IPF $[58,62] .8$-isoprostane has also been reported to be elevated in other forms of fibrotic ILD. [82, 89] MDA, another marker of lipid peroxidation, was not elevated in EBC of IPF patients compared the healthy controls [61]. However, the authors speculated that this may have been reflective of a treatment effect as the majority of the IPF patients were receiving either oral corticosteroids or $\mathrm{N}$-acetylcysteine. Additional markers of oxidative stress such as ethane have been reported to be higher in exhaled breath of patients with IPF and other forms of ILD [90].

Another study reported differences in concentration of metallic elements in EBC of patients with IPF compared to controls [59]. Metal workers are overrepresented in the IPF population and there is speculation that metal dust may be implicated in the disease process [91, 92]. The authors identified that nickel, chromium and silicon were present in higher concentrations in IPF patients and cobalt, iron, copper, selenium and molybdenum were higher in controls. This is inconsistent with a previously reported study using bronchoalveolar lavage fluid (BALF) which showed lower levels of chromium in IPF compared to controls and higher levels of iron [93].

Cytokines, such as tumour necrosis factor- $\alpha$ (TNF- $\alpha$ ) and TGF- $\beta$, have been strongly implicated in cell signalling in IPF $[94,95]$. However no significant differences were noted in levels of 42 cytokines in EBC of patients with IPF compared to controls [55]. LPA, a bioactive lysophospholipid which is believed to have a role in fibroblast migration, has been shown to be elevated in BALF of IPF patients [96]. One study did identify elevated levels of 22:4 LPA, a single subspecies of LPA, in IPF EBC [63], however total LPA levels were not significantly different. A recent phase II trial of a selective inhibitor of autotaxin (GLPG1690), a key enzyme in the production of LPA, produced promising safety and efficacy results as well as targeted reduction in plasma concentrations of another subspecies of LPA, C18:2 [97]. In the breath study, mean EBC levels of 18:2 LPA were higher IPF patients compared to controls, although not significantly [63], however studies are warranted to assess potential as a prognostic and therapeutic biomarker.

The evidence for EBC biomarkers in IPF is limited. These were primarily exploratory studies involving small cohorts and apart from 8-isoprostane, have not been 
reproduced. Currently a biomarker with diagnostic potential has not been identified. There is no evidence that EBC biomarkers distinguish between IPF and other forms of fibrotic ILD. Likewise, evidence is limited regarding their value as a prognostic marker. Levels of 8-isoprostane and $\mathrm{H}_{2} \mathrm{O}_{2}$ did appear to have a negative correlation with $\mathrm{D}_{\mathrm{LCO}} \%$ predicted in IPF but no relationship with other lung function parameters [58]. Another study suggested no correlation between in EBC $\mathrm{H}_{2} \mathrm{O}_{2}$ and lung function in 21 patients with mixed ILD including eight patients with IPF [98]. EBC is an appealing method of breath analysis, particularly as a liquid sample is obtained allowing a variety of analytical methods to be performed including specific assays, metabolomic and proteomic techniques. One possible disadvantage to EBC measurement in interstitial lung diseases, is that the technique predominantly samples respiratory lining fluid and may not accurately reflect a disease process in the lung interstitium. 8-isoprostane and $\mathrm{H}_{2} \mathrm{O}_{2}$ have both been reported to be elevated in airways disease [99-103], while MDA was shown to be higher in patients with asthma, COPD and bronchiectasis compared to controls [61]. $\mathrm{H}_{2} \mathrm{O}_{2}$ levels have been reported to be lower in patients with mixed ILD compared to obstructive lung disease [104]. Identification of molecules with a high specificity for interstitial fibrosis may be challenging using EBC as they are likely to be present in extremely small concentrations. One metabolomic study in EBC identified a novel metabolite which could consistently discriminate between IPF and healthy controls [64]. Unfortunately in this small pilot study, the metabolite could not be identified but this work shows promise and suggests that further work in this field is warranted.

VOCs offer a promising alternative source of breath biomarkers in IPF. The advantage of breath volatiles is that they could potentially travel from the blood or interstitium unaltered before detection in exhaled breath and therefore contain metabolites with high specificity for the fibrotic process. VOC work has been limited in IPF to date. Yamada et al [66] undertook a breathomic study using multicapillary column ion mobility spectrometry. They identified five compounds which could discriminate between IPF and healthy controls to varying degrees of accuracy. Isoprene carried the highest diagnostic accuracy with an area under the receiver operative characteristic curve (AUROC) of 0.81. Isoprene is a by-product of normal cholesterol synthesis and elevated levels have been noted a variety of disease states [105, 106], and therefore may be of limited use as a specific biomarker in IPF. Interestingly, lower levels of exhaled isoprene have been reported in advanced fibrosis of the liver [107]. P-cymene, which demonstrated an AUROC of 0.80, may show the most promise as a clinical biomarker as it displayed the strongest correlation with markers of disease severity. P-cymene is thought to have anti-oxidant properties and its reduction in IPF may correlate with the putative theory of increased oxidative stress [108]. This was the largest of the included studies with 95 subjects recruited. Despite this there were issues with case-control matching as the control group were significantly younger than the IPF group and were also not matched for gender and smoking history. However, this study highlights the potential for breathomic discovery of novel biomarker with both diagnostic and prognostic potential. Once specific biomarkers or patterns of biomarkers ("breathprints") have been identified, tailored diagnostic tools such as electronic noses which are more accessible in the clinical setting, could be developed. "E-noses" capable of detecting VOCs have been successfully used to phenotype and monitor treatment response in a number of conditions including COPD and obstructive sleep apnoea [109-111].

The process of biomarker development is often described as the "biomarker pipeline" and thus far none of the potential candidates have progressed past the biomarker discovery phase [112]. It can take decades to translate from the discovery phase to a clinically validated biomarker and the results of this systematic review likely reflect the fact that biomarker development in IPF remains in its infancy. Studies of blood biomarkers in IPF, in which there has been a larger body of work, have thus far failed to identify a candidate with sufficient diagnostic or prognostic accuracy $[5,113]$. The pathophysiology of IPF is complex and our understanding of the multiple processes and pathways is evolving [114]. This is a double edged sword as multiple potential biomarker candidates may exist, but identifying an individual marker which independently correlates with disease activity is extremely challenging. Likewise, development of biomarkers in IPF is particularly difficult due to lack of a gold standard diagnostic test. Diagnosis is made on consensus from a combination of available information, predominantly radiological, and it is not uncommon for this to be a "working diagnosis" $[115,116]$. Uncertainty of the accuracy of the reference standard inherently limits the reliability of the potential biomarker. It would be unfeasible to perform a biomarker study solely in patients with biopsy proven disease, as these are performed infrequently and generally in a younger, non-representative cohort [8]. VOCs have been measured in the "headspace" of in-vitro models of disease, for example lung cancer cell lines [117], however it is difficult to replicate IPF in cellular models [118].

The hope is that biomarker discovery studies inform our understanding of the pathophysiology of IPF and improve accuracy of diagnosis. In addition, novel biomarkers may be able distinguish some of the phenotypes that appear to exist within IPF [10]. Progress is certainly 
required if a clinically relevant breath biomarker is to emerge in IPF. Further breathomics studies are warranted. Longitudinal studies would be beneficial as this would increase the data pool considerably and allow individual reproducibility to be assessed. It would also provide the opportunity to better evaluate the impact of initiating treatment on biomarker levels, an issue which may confound cross-sectional studies.

\section{Limitations}

There are several limitations to this systematic review. We defined IPF based on international consensus guidelines $[2,50]$. This necessitated excluding studies involving patients that did not meet these diagnostic standards. One of these studies included patients with a diagnosis of CFA, pre-dating diagnostic guidelines [72]. This may have included patients with IPF, but also those which would now be classified as NSIP. Several other studies included patients with IPF as a composite with other forms of fibrotic ILD such as NSIP, [83] CTD-ILD, [82] or HP [81]. Two studies measured breath biomarkers in IPF but made comparison with other forms of ILD rather than healthy controls $[73,90]$. This was outside the remit of this systematic review. We excluded studies that were not published in English. The search strategy identified two studies, one published in German and one in Polish, which otherwise met criteria for full text review $[119,120]$. We excluded studies presented in abstract form as insufficient detail was provided to allow accurate and comprehensive data extraction and quality assessment. These included some studies which appeared to otherwise fulfil inclusion criteria (see Additional file 2 for details).

\section{Conclusions}

In this PRISMA-compliant systematic review we identified a heterogeneous group of studies investigating a wide variety of breath biomarkers in IPF using a range of analytical techniques. Evidence for the use of specific biomarkers was inconclusive. Twenty individual biomarkers were reported to discriminate between IPF and healthy controls. Meta-analysis of three studies indicated that $\mathrm{C}_{\text {alv }} \mathrm{NO}$ levels are significantly higher in patients with IPF compared to healthy controls. $\mathrm{C}_{\text {alv }} \mathrm{NO}, 8$-isoprostone, hydrogen peroxide and p-cymene demonstrated correlation with lung function parameters in IPF patients. There was a lack of studies investigating relevant treatment options in IPF. None of the studies compared breath biomarkers in patients with IPF in relation to the presence of honeycombing. Recent studies have indicated that a "breathomic" approach may identify biomarkers with specificity for IPF $[64,66]$. This may be of significant clinical benefit as diagnosis may be challenging due to difficulties distinguishing between IPF and other fibrotic lung diseases, particularly as a large proportion of patients are not suitable for surgical lung biopsy. Larger studies with longitudinal data are required to identify biomarkers with diagnostic and prognostic potential.

\section{Additional files}

Additional file 1: Search results per database. (DOCX $12 \mathrm{~kb}$ )

Additional file 2: Studies excluded following full text review (DOCX $18 \mathrm{~kb}$ )

Additional file 3: Summary of QUADAS-2 assessment for each study. (DOCX $15 \mathrm{~kb})$

\section{Abbreviations}

22:4 LPA: Docosatraenoyl lysophosphatidic acid; AUROC: Area under the receiver operative characteristic curve; BALF: Bronchoalveolar lavage fluid; C: Carbon; $\mathrm{C}_{\text {alv }} \mathrm{NO}$ : Alveolar nitric oxide; $\mathrm{C}_{\mathrm{aw}} \mathrm{NO}$ : Airway wall nitric oxide; CFA: Cryptogenic fibrosing alveolitis; Co: Cobalt; COPD: Chronic obstructive pulmonary disease; Cr: Chromium; CTD: Connective tissue disease; Cu: Copper; CysLT: Cysteinyl leukotriene; $D_{a w} N O$ : Diffusion capacity for nitric oxide; $D_{\mathrm{LCO}}$ : Diffusion capacity for carbon monoxide; EBC: Exhaled breath condensate; ElA: Enzyme immunoassay; Fe: Iron; FeNO: Fractionated exhaled nitric oxide; FVC: Forced vital capacity; $\mathrm{H}$ : Hydrogen; $\mathrm{H}_{2} \mathrm{O}_{2}$ : Hydrogen peroxide; HP: Hypersensitivity pneumonitis; HPLC: High performance liquid chromatography; HRMS: High resolution mass spectrometry; ICP: Inductively coupled plasma; ILD: Interstitial lung disease; IMS: Ion mobility spectrometry; IPF: Idiopathic pulmonary fibrosis; Jaw NO: Airway flux of nitric oxide; KL6: Krebs von den Lungen-6; LC: Liquid chromatography; LPA: Lysophosphatidic acid; MCC: Multi-capillary column;

MDA: Malondialdehyde; MeSH: Medical subject headings; MMP7: Matrix metalloproteinase-7; Mo: Molybdenum; MS: Mass spectroscopy; N: Nitrogen; Ni: Nickel; NO: Nitric oxide; NSIP: Non-specific interstitial pneumonia; O: Oxygen; ppb: Part per billion; PRISMA: Preferred reporting items for systematic reviews and meta-analyses; PROFILE: Prospective observation of fibrosis in the lung clinical endpoints; QUADAS-2: Quality assessment tool for diagnostic accuracy studies; SD: Standard deviation; Se: Selenium;

SE: Standard error; Si: Silicon; SP-A: Surfactant protein-A; SP-D: Surfactant protein-D; TGF- $\beta$ : Transforming growth factor- $\beta$; TNF-a: Tumour necrosis factor-a; UHPLC: Ultra-high performance liquid chromatography; USA: United States of America; VA: Alveolar volume; VC: Vital capacity; VOC: Volatile organic compound

\section{Acknowledgements}

Not applicable

\section{Funding}

No funding was received for this systematic review.

\section{Availability of data and materials}

Not applicable

\section{Authors' contributions}

$\mathrm{CH}, \mathrm{DT}, \mathrm{AMW}$ and SJF were involved in study design. $\mathrm{CH}$ and DT performed the literature review and data synthesis. $\mathrm{CH}$ prepared the manuscript. DT, AMW, NC, CL and SJF contributed to drafting the manuscript. All authors approved the final manuscript.

\section{Authors' information}

Not applicable

Ethics approval and consent to participate Not applicable 


\section{Consent for publication}

Not applicable

\section{Competing interests}

$\mathrm{CH}, \mathrm{NC}$ and SJF have a received a research grant from Boehringer Ingelheim. NC has received personal fees from Boehringer Ingelheim and Roche to participate in advisory boards and support to attend educational meetings from Roche and Intermune. DT, AMW, and $\mathrm{CL}$ have no competing interests.

\section{Publisher's Note}

Springer Nature remains neutral with regard to jurisdictional claims in published maps and institutional affiliations.

\section{Author details}

'Division of Infection, Immunity and Respiratory Medicine, School of Biological Sciences, Faculty of Biology, Medicine and Health, The University of Manchester, Manchester, UK. ${ }^{2}$ Norwich Medical School, University of East Anglia, Norwich, UK. ${ }^{3}$ North West Lung Centre, Manchester University NHS Foundation Trust, Manchester, UK.

\section{Received: 16 August 2018 Accepted: 1 January 2019}

\section{Published online: 11 January 2019}

\section{References}

1. Hutchinson J, Fogarty A, Hubbard R, McKeever T. Global incidence and mortality of idiopathic pulmonary fibrosis: a systematic review. Eur Respir J. 2015;46(3):795-806.

2. Raghu G, Collard HR, Egan JJ, Martinez FJ, Behr J, Brown KK, Colby TV, Cordier JF, Flaherty KR, Lasky JA, Lynch DA, Ryu JH, Swigris JJ, Wells AU, Ancochea J, Bouros D, Carvalho C, Costabel U, Ebina M, Hansell DM, Johkoh T, Kim DS, King TE Jr, Kondoh Y, Myers J, Muller NL, Nicholson AG, Richeldi L, Selman M, Dudden RF, Griss BS, Protzko SL, Schunemann HJ. An official ATS/ERS/JRS/ALAT statement: idiopathic pulmonary fibrosis: evidence-based guidelines for diagnosis and management. Am J Respir Crit Care Med. 2011; 183(6):788-824.

3. Wells AU, Costabel U, Poletti V, Crestani B, Egan J, Margaritopoulos G, Antoniou K. Challenges in IPF diagnosis, current management and future perspectives. Sarcoidosis Vasc Diffuse Lung Dis. 2015;32(Suppl 1):28-35.

4. Daccord C, Maher TM. Recent advances in understanding idiopathic pulmonary fibrosis. F1000Res. 2016; 5(F1000 Faculty Rev):1046.

5. Raghu G, Remy-Jardin M, Myers JL, Richeldi L, Ryerson CJ, Lederer DJ, Behr J, Cottin V, Danoff SK, Morell F, Flaherty KR, Wells A, Martinez FJ, Azuma A, Bice TJ, Bouros D, Brown KK, Collard HR, Duggal A, Galvin L, Inoue Y, Jenkins RG, Johkoh T, Kazerooni EA, Kitaichi M, Knight SL, Mansour G, Nicholson AG, Pipavath SNJ, Buendia-Roldan I, Selman M, Travis WD, Walsh S, Wilson KC. American Thoracic society ERSJRS, Latin American Thoracic S. diagnosis of idiopathic pulmonary fibrosis. An official ATS/ERS/JRS/ALAT clinical practice guideline. Am J Respir Crit Care Med. 2018;198(5):e44-68.

6. Flaherty KR, King TE Jr, Raghu G, Lynch JP 3rd, Colby TV, Travis WD, Gross BH, Kazerooni EA, Toews GB, Long Q, Murray S, Lama VN, Gay SE, Martinez FJ. Idiopathic interstitial pneumonia: what is the effect of a multidisciplinary approach to diagnosis? Am J Respir Crit Care Med. 2004;170(8):904-10.

7. Walsh SL, Calandriello L, Sverzellati N, Wells AU, Hansell DM, Consort UIPO. Interobserver agreement for the ATS/ERS/JRS/ALAT criteria for a UIP pattern on CT. Thorax. 2016;71(1):45-51.

8. Hutchinson JP, McKeever TM, Fogarty AW, Navaratnam V, Hubbard RB. Surgical lung biopsy for the diagnosis of interstitial lung disease in England: 1997-2008. Eur Respir J. 2016:48(5):1453-61.

9. Bjoraker JA, Ryu JH, Edwin MK, Myers JL, Tazelaar HD, Schroeder DR, Offord KP. Prognostic significance of histopathologic subsets in idiopathic pulmonary fibrosis. Am J Respir Crit Care Med. 1998;157(1):199-203.

10. Ley B, Collard HR, King TE Jr. Clinical course and prediction of survival in idiopathic pulmonary fibrosis. Am J Respir Crit Care Med. 2011;183(4):431-40.

11. Raghu G, Collard HR, Anstrom KJ, Flaherty KR, Fleming TR, King TE Jr, Martinez FJ, Brown KK. Idiopathic pulmonary fibrosis: clinically meaningful primary endpoints in phase 3 clinical trials. Am J Respir Crit Care Med. 2012; 185(10):1044-8.

12. Latsi PI, du Bois RM, Nicholson AG, Colby TV, Bisirtzoglou D, Nikolakopoulou A, Veeraraghavan S, Hansell DM, Wells AU. Fibrotic idiopathic interstitial pneumonia: the prognostic value of longitudinal functional trends. Am J Respir Crit Care Med. 2003;168(5):531-7.

13. Jegal Y, Kim DS, Shim TS, Lim CM, Do Lee S, Koh Y, Kim WS, Kim WD, Lee JS, Travis WD, Kitaichi M, Colby TV. Physiology is a stronger predictor of survival than pathology in fibrotic interstitial pneumonia. Am J Respir Crit Care Med. 2005;171(6):639-44.

14. Collard HR, King TE Jr, Bartelson BB, Vourlekis JS, Schwarz MI, Brown KK. Changes in clinical and physiologic variables predict survival in idiopathic pulmonary fibrosis. Am J Respir Crit Care Med. 2003;168(5):538-42.

15. King TE Jr, Tooze JA, Schwarz MI, Brown KR, Cherniack RM. Predicting survival in idiopathic pulmonary fibrosis: scoring system and survival model. Am J Respir Crit Care Med. 2001;164(7):1171-81.

16. Wells AU. Forced vital capacity as a primary end point in idiopathic pulmonary fibrosis treatment trials: making a silk purse from a sow's ear. Thorax. 2013;68(4):309-10.

17. Pellegrino R, Viegi G, Brusasco V, Crapo RO, Burgos F, Casaburi R, Coates A, van der Grinten CP, Gustafsson P, Hankinson J, Jensen R, Johnson DC, Maclntyre N, McKay R, Miller MR, Navajas D, Pedersen OF, Wanger J. Interpretative strategies for lung function tests. Eur Respir J 2005;26(5):948-968.

18. du Bois RM, Albera C, Bradford WZ, Costabel U, Leff JA, Noble PW, Sahn SA, Valeyre D, Weycker D, King TE Jr. 6-minute walk distance is an independent predictor of mortality in patients with idiopathic pulmonary fibrosis. Eur Respir J. 2014;43(5):1421-9.

19. Wells AU, Desai SR, Rubens MB, Goh NS, Cramer D, Nicholson AG, Colby TV, du Bois RM, Hansell DM. Idiopathic pulmonary fibrosis: a composite physiologic index derived from disease extent observed by computed tomography. Am J Respir Crit Care Med. 2003;167(7):962-9.

20. Ley B, Ryerson CJ, Vittinghoff E, Ryu JH, Tomassetti S, Lee JS, Poletti V, Buccioli M, Elicker BM, Jones KD, King TE Jr. Collard HR. a multidimensional index and staging system for idiopathic pulmonary fibrosis. Ann Intern Med. 2012;156(10):684-91.

21. Martinez FJ, Chisholm A, Collard HR, Flaherty KR, Myers J, Raghu G, Walsh SLF, White ES, Richeldi L. The diagnosis of idiopathic pulmonary fibrosis: current and future approaches. Lancet Respir Med. 2017;5(1):61-71.

22. Jenkins G, Goodwin A. Novel approaches to pulmonary fibrosis. Clin Med (Lond). 2014;14(Suppl 6):s45-9.

23. Okamoto T, Fujii M, Furusawa H, Tsuchiya K, Miyazaki Y, Inase N. The usefulness of KL-6 and SP-D for the diagnosis and management of chronic hypersensitivity pneumonitis. Respir Med. 2015;109(12):1576-81.

24. Satoh H, Kurishima K, Ishikawa H, Ohtsuka M. Increased levels of KL-6 and subsequent mortality in patients with interstitial lung diseases. J Intern Med. 2006;260(5):429-34.

25. Ishii H, Mukae H, Kadota J, Kaida H, Nagata T, Abe K, Matsukura S, Kohno S. High serum concentrations of surfactant protein a in usual interstitial pneumonia compared with non-specific interstitial pneumonia. Thorax. 2003:58(1):52-7.

26. Kinder BW, Brown KK, McCormack FX, Ix JH, Kervitsky A, Schwarz MI, King TE Jr. Serum surfactant protein-a is a strong predictor of early mortality in idiopathic pulmonary fibrosis. Chest. 2009;135(6):1557-63.

27. Barlo NP, van Moorsel CH, Ruven HJ, Zanen P, van den Bosch JM, Grutters JC. Surfactant protein-D predicts survival in patients with idiopathic pulmonary fibrosis. Sarcoidosis Vasc Diffuse Lung Dis. 2009;26(2):155-61.

28. Rosas IO, Richards TJ, Konishi K, Zhang Y, Gibson K, Lokshin AE, Lindell KO, Cisneros J, Macdonald SD, Pardo A, Sciurba F, Dauber J, Selman M, Gochuico BR, Kaminski N. MMP1 and MMP7 as potential peripheral blood biomarkers in idiopathic pulmonary fibrosis. PLoS Med. 2008;5(4):e93.

29. Jenkins RG, Simpson JK, Saini G, Bentley JH, Russell A-M, Braybrooke R, Molyneaux PL, McKeever TM, Wells AU, Flynn A, Hubbard RB, Leeming DJ, Marshall RP, Karsdal MA, Lukey PT, Maher TM. Longitudinal change in collagen degradation biomarkers in idiopathic pulmonary fibrosis: an analysis from the prospective, multicentre PROFILE study. Lancet Respir Med. 2015;3(6):462-72

30. Maher TM, Oballa E, Simpson JK, Porte J, Habgood A, Fahy WA, Flynn A, Molyneaux PL, Braybrooke R, Divyateja H, Parfrey H, Rassl D, Russell A-M, Saini G, Renzoni EA, Duggan A-M, Hubbard R, Wells AU, Lukey PT, Marshall RP, Jenkins RG. An epithelial biomarker signature for idiopathic pulmonary fibrosis: an analysis from the multicentre PROFILE cohort study. Lancet Respir Med. 2017;5(12):946-55.

31. Kharitonov SA, Barnes PJ. Exhaled markers of pulmonary disease. Am J Respir Crit Care Med. 2001;163(7):1693-722. 
32. Petsky HL, Kew KM, Turner C, Chang AB. Exhaled nitric oxide levels to guide treatment for adults with asthma. Cochrane Database Syst Rev. 2016;9: CD011440.

33. Dweik RA, Boggs PB, Erzurum SC, Irvin CG, Leigh MW, Lundberg JO, Olin AC, Plummer AL, Taylor DR. An official ATS clinical practice guideline: interpretation of exhaled nitric oxide levels (FENO) for clinical applications. Am J Respir Crit Care Med. 2011;184(5):602-15.

34. British Thoracic Society/Scottish Intercollegiate Guidelines Network. British guideline on the management of asthma. National clinical guideline. 2016 [Available from: http://www.sign.ac.uk/assets/sign153.pdf. Date last accessed 01/02/2018

35. National Institute for Health and Care Excellence. Asthma: diagnosis, monitoring and chronic asthma management. ng80 London2017 [Available from: https://www.nice.org.uk/guidance/ng80. Date last accessed 01/02/2018

36. Tsoukias NM, George SC. A two-compartment model of pulmonary nitric oxide exchange dynamics. J Appl Physiol (Bethesda, Md: 1985). 1998;85(2): 653-66.

37. George SC, Hogman M, Permutt S, Silkoff PE. Modeling pulmonary nitric oxide exchange. J Appl Physiol (Bethesda, Md: 1985). 2004;96(3):831-9.

38. Effros RM, Hoagland KW, Bosbous M, Castillo D, Foss B, Dunning M, Gare M, Lin W, Sun F. Dilution of respiratory solutes in exhaled condensates. Am J Respir Crit Care Med. 2002;165(5):663-9.

39. Horvath I, Hunt J, Barnes PJ, Alving K, Antczak A, Baraldi E, Becher G, van Beurden WJ, Corradi M, Dekhuijzen R, Dweik RA, Dwyer T, Effros R, Erzurum S, Gaston B, Gessner C, Greening A, Ho LP, Hohlfeld J, Jobsis Q, Laskowski D, Loukides S, Marlin D, Montuschi P, Olin AC, Redington AE, Reinhold P, van Rensen EL, Rubinstein I, Silkoff P, Toren K, Vass G, Vogelberg C, Wirtz H. Exhaled breath condensate: methodological recommendations and unresolved questions. Eur Respir J 2005;26(3):523-548.

40. Boots AW, van Berkel J, Dallinga JW, Smolinska A, Wouters EF, van Schooten FJ. The versatile use of exhaled volatile organic compounds in human health and disease. J Breath Res. 2012;6(2)

41. van de Kant KDG, van der Sande $L$, Jobsis $Q$, van Schayck OCP, Dompeling E. Clinical use of exhaled volatile organic compounds in pulmonary diseases: a systematic review. Respir Res. 2012;13:117.

42. van der Schee MP, Paff T, Brinkman P, van Aalderen WMC, Haarman EG, Sterk PJ. Breathomics in Lung Disease. Chest. 2015;147(1):224-31.

43. Fowler SJ. Breath analysis for label-free characterisation of airways disease. Eur Respir J 2018;51:1702586

44. Rufo JC, Madureira J, Fernandes EO, Moreira A. Volatile organic compounds in asthma diagnosis: a systematic review and meta-analysis. Allergy. 2016; 71(2):175-88.

45. Bos LD, Sterk PJ, Fowler SJ. Breathomics in the setting of asthma and chronic obstructive pulmonary disease. J Allergy Clin Immunol. 2016;138(4):970-6.

46. van Oort P, Povoa P, Schnabel R, Dark P, Artigas A, Bergmans D, Felton T, Coelho L, Schultz MJ, Fowler SJ, Bos L. The potential role of exhaled breath analysis in the diagnostic process of pneumonia - a systematic review. J Breath Res. 2018;12(2):024001

47. Zhou J, Huang ZA, Kumar U, Chen DDY. Review of recent developments in determining volatile organic compounds in exhaled breath as biomarkers for lung cancer diagnosis. Anal Chim Acta. 2017;996:1-9.

48. Scarlata S, Pennazza G, Santonico M, Pedone C, Antonelli Incalzi R. Exhaled breath analysis by electronic nose in respiratory diseases. Expert Rev Mol Diagn. 2015;15(7):933-56

49. Moher D, Liberati A, Tetzlaff J, Altman DG, Group P. Preferred reporting items for systematic reviews and meta-analyses: the PRISMA statement. PLoS Med. 2009;6(7):e1000097.

50. American Thoracic Society/European Respiratory Society International Multidisciplinary Consensus Classification of the Idiopathic Interstitial Pneumonias. This joint statement of the American Thoracic Society (ATS), and the European Respiratory Society (ERS) was adopted by the ATS board of directors, June 2001 and by the ERS executive committee, June 2001. Am J Respir Crit Care Med. 2002;165(2):277-304.

51. Whiting PF, Rutjes AW, Westwood ME, Mallett S, Deeks JJ, Reitsma JB, Leeflang MM, Sterne JA, Bossuyt PM. QUADAS-2: a revised tool for the quality assessment of diagnostic accuracy studies. Ann Intern Med. 2011 155(8):529-36.

52. Wallace BC, Dahabreh IJ, Trikalinos TA, Lau J, Trow P, Schmid CH. Closing the gap between methodologists and end-users: $\mathrm{R}$ as a computational Back-end. J Stat Softw. 2012;49(5):15.
53. Horváth I, Barnes PJ, Loukides S, Sterk PJ, Högman M, Olin A-C, Amann A, Antus B, Baraldi E, Bikov A, Boots AW, Bos LD, Brinkman P, Bucca C, Carpagnano GE, Corradi M, Cristescu S, de Jongste JC, Dinh-Xuan A-T, Dompeling E, Fens N, Fowler S, Hohlfeld Jens M, Holz O, Jöbsis Q, Van De Kant K, Knobel Hugo H, Kostikas K, Lehtimäki L, Lundberg JO, Montuschi P, Van Muylem A, Pennazza G, Reinhold P, Ricciardolo FLM, Rosias P, Santonico M, van der Schee Marc P, van Schooten F-J, Spanevello A, Tonia T, Vink TJ. A European Respiratory Society technical standard: exhaled biomarkers in lung disease. Eur Respir J. 2017;49(4):1600965.

54. American Thoracic S, European Respiratory S. ATS/ERS recommendations for standardized procedures for the online and offline measurement of exhaled lower respiratory nitric oxide and nasal nitric oxide, 2005. Am J Respir Crit Care Med. 2005;171(8):912-30.

55. Furukawa K, Sugiura H, Matsunaga K, Ichikawa T, Koarai A, Hirano T, Yanagisawa S, Minakata Y, Akamatsu K, Kanda M, Nishigai M, Ichinose M. Increase of nitrosative stress in patients with eosinophilic pneumonia. Respir Res. 2011;12.

56. Zhao Y, Cui A, Wang F, Wang XJ, Chen X, Jin ML, Huang KW. Characteristics of pulmonary inflammation in combined pulmonary fibrosis and emphysema. Chin Med J. 2012;125(17):3015-21.

57. Cameli P, Barbagli E, Rottoli P. Exhaled nitric oxide is not increased in pulmonary sarcoidosis. Sarcoidosis Vasc Diffuse Lung Dis. 2016;33(1):39-40.

58. Psathakis K, Mermigkis D, Papatheodorou G, Loukides S, Panagou P, Polychronopoulos V, Siafakas NM, Bouros D. Exhaled markers of oxidative stress in idiopathic pulmonary fibrosis. Eur J Clin Investig. 2006;36(5):362-7.

59. Corradi M, Acampa O, Goldoni M, Adami E, Apostoli P, de Palma G, Pesci A, Mutti A. Metallic elements in exhaled breath condensate of patients with interstitial lung diseases. J Breath Res. 2009;3(4).

60. Rihak V, Zatloukal P, Chladkova J, Zimulova A, Havlinova Z, Chladek J. Nitrite in exhaled breath condensate as a marker of nitrossative stress in the airways of patients with asthma, COPD, and idiopathic pulmonary fibrosis. J Clin Lab Anal. 2010;24(5):317-22.

61. Bartoli ML, Novelli F, Costa F, Malagrino L, Melosini L, Bacci E, Cianchetti S, Dente FL, Di Franco A, Vagaggini B, Paggiaro PL. Malondialdehyde in exhaled breath condensate as a marker of oxidative stress in different pulmonary diseases. Mediat Inflamm. 2011;891752.

62. Shimizu Y, Dobashi K, Sano T, Yamada M. Rock activation in Lung of idiopathic pulmonary fibrosis with oxidative stress. Int J Immunopathol Pharmacol. 2014;27(1):37-44

63. Montesi SB, Mathai SK, Brenner LN, Gorshkova IA, Berdyshev EV, Tager AM, Shea BS. Docosatetraenoyl LPA is elevated in exhaled breath condensate in idiopathic pulmonary fibrosis. BMC Pulm Med. 2014;14 (1) (no pagination)(5).

64. Rindlisbacher B, Strebel C, Guler SA, Kollar A, Geiser TK, Fiedler GM, Leichtle AB, Bovet C, Funke M. Exhaled breath condensate as a potential biomarker tool for idiopathic pulmonary fibrosis - a pilot study. J Breath Res. 2017

65. Mazzone PJ, Hammel J, Dweik R, Na J, Czich C, Laskowski D, Mekhail T. Diagnosis of lung cancer by the analysis of exhaled breath with a colorimetric sensor array. Thorax. 2007;62(7):565-8.

66. Yamada Y, Yamada G, Otsuka M, Nishikiori H, Ikeda K, Umeda Y, Ohnishi H, Kuronuma K, Chiba H, Baumbach Jl, Takahashi H. Volatile organic compounds in exhaled breath of idiopathic pulmonary fibrosis for discrimination from healthy subjects. Lung. 2017;195(2):247-54.

67. Ono E, Mita H, Taniguchi M, Higashi N, Tsuburai T, Miyazaki E, Kumamoto T, Akiyama K. Comparison of cysteinyl leukotriene concentrations between exhaled breath condensate and bronchoalveolar lavage fluid. Clin Exp Allergy. 2008;38(12):1866-74.

68. Kotecha J, Shulgina L, Sexton DW, Atkins CP, Wilson AM. Plasma vascular endothelial growth factor concentration and alveolar nitric oxide as potential predictors of Disease progression and mortality in idiopathic pulmonary fibrosis. J Clin Med. 2016;5(9):80.

69. Condorelli P, Shin HW, Aledia AS, Silkoff PE, George SCA. Simple technique to characterize proximal and peripheral nitric oxide exchange using constant flow exhalations and an axial diffusion model. J Appl Physiol (Bethesda, Md: 1985). 2007;102(1):417-25.

70. Hou YC, Janczuk A, Wang PG. Current trends in the development of nitric oxide donors. Curr Pharm Des. 1999;5(6):417-41.

71. Hsu YC, Wang LF, Chien YW. Nitric oxide in the pathogenesis of diffuse pulmonary fibrosis. Free Radic Biol Med. 2007;42(5):599-607. 
72. Paredi P, Kharitonov SA, Loukides S, Pantelidis P, du Bois RM, Barnes PJ. Exhaled nitric oxide is increased in active fibrosing alveolitis. Chest. 1999; 115(5):1352-6.

73. Guilleminault L, Saint-Hilaire A, Favelle O, Caille A, Boissinot E, Henriet AC, Diot P, Marchand-Adam S. Can exhaled nitric oxide differentiate causes of pulmonary fibrosis? Respir Med. 2013;107(11):1789-96.

74. Ojanguren I, Cruz MJ, Villar A, Sanchez-Ortiz M, Morell F, Munoz X. Changes in $\mathrm{PH}$ in exhaled breath condensate after specific bronchial challenge test in patients with chronic hypersensitivity pneumonitis: a prospective study. BMC Pulm Med. 2015;15:109.

75. Toren K, Murgia N, Schioler L, Bake B, Olin AC. Reference values of fractional excretion of exhaled nitric oxide among non-smokers and current smokers. BMC Pulm Med. 2017;17(1):118.

76. Hogman M, Thornadtsson A, Liv P, Hua-Huy T, Dinh-Xuan AT, Tufvesson E, Dressel H, Janson C, Koskela K, Oksa P, Sauni R, Uitti J, Moilanen E, Lehtimak $L$. Effects of growth and aging on the reference values of pulmonary nitric oxide dynamics in healthy subjects. J Breath Res. 2017;11(4):047103.

77. Gregus M, Foret F, Kindlova D, Pokojova E, Plutinsky M, Doubkova M, Merta Z, Binkova I, Skrickova J, Kuban P. Monitoring the ionic content of exhaled breath condensate in various respiratory diseases by capillary electrophoresis with contactless conductivity detection. J Breath Res. 2015; 9(2):027107.

78. Tiev KP, Le-Dong NN, Duong-Quy S, Hua-Huy T, Cabane J, Dinh-Xuan AT. Exhaled nitric oxide, but not serum nitrite and nitrate, is a marker of interstitial lung disease in systemic sclerosis. Nitric Oxide. 2009;20(3):200-6.

79. Tiev KP, Cabane J, Aubourg F, Kettaneh A, Ziani M, Mouthon L, Duong-Quy S, Fajac I, Guillevin L, Dinh-Xuan AT. Severity of scleroderma lung disease is related to alveolar concentration of nitric oxide. Eur Respir J. 2007;30(1):26-30

80. Girgis RE, Gugnani MK, Abrams J, Mayes MD. Partitioning of alveolar and conducting airway nitric oxide in scleroderma Lung Disease. Am J Respir Crit Care Med. 2002;165(12):1587-91.

81. Lehtimaki L, Kankaanranta H, Saarelainen S, Hahtola P, Jarvenpaa R, Koivula T, Turjanmaa $V$, Moilanen E. Extended exhaled NO measurement differentiates between alveolar and bronchial inflammation. Am J Respir Crit Care Med. 2001;163(7):1557-61.

82. Chow S, Thomas PS, Malouf M, Yates DH. Exhaled breath condensate (EBC) biomarkers in pulmonary fibrosis. J Breath Res. 2012;6(1).

83. Cameli $P$, Bargagli $E$, Refini RM, Pieroni MG, Bennett $D$, Rottoli $P$. Exhaled nitric oxide in interstitial lung diseases. Respir Physiol Neurobiol. 2014;197:46-52.

84. Sandrini A, Johnson AR, Thomas PS, Yates DH. Fractional exhaled nitric oxide concentration is increased in asbestosis and pleural plaques. Respirology. 2006;11(3):325-9.

85. Lehtonen H, Oksa P, Lehtimaki L, Sepponen A, Nieminen R, Kankaanranta H, Saarelainen S, Jarvenpaa R, Uitti J, Moilanen E. Increased alveolar nitric oxide concentration and high levels of leukotriene B-4 and 8isoprostane in exhaled breath condensate in patients with asbestosis. Thorax. 2007;62(7):602-7.

86. Network TIPFCR. Prednisone, azathioprine, and N-acetylcysteine for pulmonary fibrosis. N Engl J Med. 2012;366(21):1968-77.

87. Bargagli E, Olivieri C, Bennett D, Prasse A, Muller-Quernheim J, Rottoli P. Oxidative stress in the pathogenesis of diffuse lung diseases: a review. Respir Med. 2009;103(9):1245-56.

88. Fois AG, Paliogiannis P, Sotgia S, Mangoni AA, Zinellu E, Pirina P, Carru C, Zinellu A. Evaluation of oxidative stress biomarkers in idiopathic pulmonary fibrosis and therapeutic applications: a systematic review. Respir Res. 2018; 19(1):51.

89. Chow S, Campbell C, Sandrini A, Thomas PS, Johnson AR, Yates DH. Exhaled breath condensate biomarkers in asbestos-related lung disorders. Respir Med. 2009;103(8):1091-7.

90. Kanoh S, Kobayashi H, Motoyoshi K. Exhaled ethane: an in vivo biomarker of lipid peroxidation in interstitial lung diseases. Chest. 2005;128(4):2387-92.

91. Hubbard R, Cooper M, Antoniak M, Venn A, Khan S, Johnston I, Lewis S, Britton J. Risk of cryptogenic fibrosing alveolitis in metal workers. Lancet. 2000;355(9202):466-7.

92. Hubbard R, Lewis S, Richards K, Johnston I, Britton J. Occupational exposure to metal or wood dust and aetiology of cryptogenic fibrosing alveolitis. Lancet. 1996;347(8997):284-9.

93. Bargagli E, Monaci F, Bianchi N, Bucci C, Rottoli P. Analysis of trace elements in bronchoalveolar lavage of patients with diffuse lung diseases. Biol Trace Elem Res. 2008;124(3):225-35.
94. Bagnato $\mathrm{G}$, Harari S. Cellular interactions in the pathogenesis of interstitial lung diseases. Eur Respir Rev. 2015;24(135):102-14.

95. Agostini C, Gurrieri C. Chemokine/cytokine cocktail in idiopathic pulmonary fibrosis. Proc Am Thorac Soc. 2006;3(4):357-63.

96. Tager AM, LaCamera P, Shea BS, Campanella GS, Selman M, Zhao Z, Polosukhin V, Wain J, Karimi-Shah BA, Kim ND, Hart WK, Pardo A, Blackwell TS, Xu Y, Chun J, Luster AD. The lysophosphatidic acid receptor LPA1 links pulmonary fibrosis to lung injury by mediating fibroblast recruitment and vascular leak. Nat Med. 2008;14(1):45-54.

97. Maher TM, van der Aar EM, Van de Steen O, Allamassey L, Desrivot J, Dupont S, Fagard L, Ford P, Fieuw A, Wuyts W. Safety, tolerability, pharmacokinetics, and pharmacodynamics of GLPG1690, a novel autotaxin inhibitor, to treat idiopathic pulmonary fibrosis (FLORA): a phase 2a randomised placebo-controlled trial. Lancet Respir Med. 2018.

98. Corradi M, Pignatti P, Brunetti G, Goldoni M, Caglieri A, Nava S, Moscato G, Balbi B. Comparison between exhaled and bronchoalveolar lavage levels of hydrogen peroxide in patients with diffuse interstitial lung diseases. Acta Biomed. 2008;79(SUPPL. 1):73-8.

99. Peel AM, Crossman-Barnes CJ, Tang J, Fowler SJ, Davies GA, Wilson AM, Loke YK. Biomarkers in adult asthma: a systematic review of 8-isoprostane in exhaled breath condensate. J Breath Res. 2017;11(1):016011.

100. Montuschi P, Collins JV, Ciabattoni G, Lazzeri N, Corradi M, Kharitonov SA, Barnes PJ. Exhaled 8-isoprostane as an in vivo biomarker of lung oxidative stress in patients with COPD and healthy smokers. Am J Respir Crit Care Med. 2000;162(3 Pt 1):1175-7.

101. Makris D, Paraskakis E, Korakas P, Karagiannakis E, Sourvinos G, Siafakas NM, Tzanakis N. Exhaled breath condensate 8-isoprostane, clinical parameters, radiological indices and airway inflammation in COPD. Respiration. 2008; 75(2):138-44.

102. Teng Y, Sun P, Zhang J, Yu R, Bai J, Yao X, Huang M, Adcock IM, Barnes PJ. Hydrogen peroxide in exhaled breath condensate in patients with asthma: a promising biomarker? Chest. 2011;140(1):108-16.

103. Dekhuijzen PN, Aben KK, Dekker I, Aarts LP, Wielders PL, van Herwaarden $\mathrm{CL}$, Bast $\mathrm{A}$. Increased exhalation of hydrogen peroxide in patients with stable and unstable chronic obstructive pulmonary disease. Am J Respir Crit Care Med 1996;154(3 Pt 1):813-816.

104. Fireman E, Shtark M, Priel IE, Shiner R, Mor R, Kivity S, Fireman Z. Hydrogen peroxide in exhaled breath condensate (EBC) vs eosinophil count in induced sputum (IS) in parenchymal vs airways lung diseases. Inflammation. 2007;30(1-2):44-51

105. Ulanowska A, Kowalkowski T, Trawinska E, Buszewski B. The application of statistical methods using VOCs to identify patients with lung cancer. J Breath Res. 2011;5(4):046008

106. Mashir A, Paschke KM, van Duin D, Shrestha NK, Laskowski D, Storer MK, Yen-Lieberman B, Gordon SM, Aytekin M, Dweik RA. Effect of the influenza a (H1N1) live attenuated intranasal vaccine on nitric oxide (FE (NO)) and other volatiles in exhaled breath. J Breath Res. 2011;5(3):037107.

107. Alkhouri N, Singh T, Alsabbagh E, Guirguis J, Chami T, Hanouneh I, Grove D, Lopez R, Dweik R. Isoprene in the exhaled breath is a novel biomarker for advanced fibrosis in patients with chronic liver Disease: a pilot study. Clin Transl Gastroenterol. 2015;6:e112.

108. de Oliveira TM, de Carvalho RB, da Costa IH, de Oliveira GA, de Souza AA, de Lima SG, de Freitas RM. Evaluation of p-cymene, a natural antioxidant. Pharm Biol. 2015;53(3):423-8.

109. Scarlata S, Finamore P, Santangelo S, Giannunzio G, Pennazza G, Grasso S, Santonico M, Incalzi RA. Cluster analysis on breath print of newly diagnosed COPD patients: effects of therapy. J Breath Res. 2018;12(3): 036022.

110. Greulich T, Hattesohl A, Grabisch A, Koepke J, Schmid S, Noeske S, Nell C, Wencker M, Jorres RA, Vogelmeier CF, Kohler U, Koczulla AR. Detection of obstructive sleep apnoea by an electronic nose. Eur Respir J. 2013; 42(1):145-55.

111. Antonelli Incalzi R, Pennazza G, Scarlata S, Santonico M, Vernile C, Cortese L, Frezzotti E, Pedone C, D'Amico A. Comorbidity modulates non invasive ventilation-induced changes in breath print of obstructive sleep apnea syndrome patients. Sleep Breath. 2015;19(2):623-30.

112. Paulovich AG, Whiteaker JR, Hoofnagle AN, Wang P. The interface between biomarker discovery and clinical validation: the tar pit of the protein biomarker pipeline. Proteomics Clin Appl. 2008;2(10-11):1386-402.

113. Guiot J, Moermans C, Henket M, Corhay JL, Louis R. Blood biomarkers in idiopathic pulmonary fibrosis. Lung. 2017;195(3):273-80. 
114. Martinez FJ, Collard HR, Pardo A, Raghu G, Richeldi L, Selman M, Swigris JJ, Taniguchi H, Wells AU. Idiopathic pulmonary fibrosis. Nat Rev Dis Primers. 2017;3:17074.

115. Wells AU. Any fool can make a rule and any fool will mind it. BMC Med. 2016;14:23.

116. Cottin V. Lung biopsy in interstitial lung disease: balancing the risk of surgery and diagnostic uncertainty. Eur Respir J. 2016;48(5):1274-7.

117. Kalluri U, Naiker M, Myers MA. Cell culture metabolomics in the diagnosis of lung cancer-the influence of cell culture conditions. J Breath Res. 2014;8(2): 027109.

118. Sundarakrishnan A, Chen Y, Black LD, Aldridge BB, Kaplan DL. Engineered cell and tissue models of pulmonary fibrosis. Adv Drug Deliv Rev. 2018;129:78-94.

119. Schildge J. Nitric oxide in exhaled breath of patients with interstitial lung diseases. Pneumologie. 2011;65(3):143-8.

120. Hildebrand K, Krenke R, Pzybylowski T, Frangrat A, Gorska K, Chazan R.

Influence of bronchoscopy on nitirc oxide in exhaled air ( $\left.\mathrm{FE}_{\mathrm{NO}}\right)$. Pneumonol Alergol Pol. 2006;74(1):26-31.

Ready to submit your research? Choose BMC and benefit from:

- fast, convenient online submission

- thorough peer review by experienced researchers in your field

- rapid publication on acceptance

- support for research data, including large and complex data types

- gold Open Access which fosters wider collaboration and increased citations

- maximum visibility for your research: over $100 \mathrm{M}$ website views per year

At $\mathrm{BMC}$, research is always in progress.

Learn more biomedcentral.com/submissions 